\title{
The Determinants of Primary Employment in U.S. States
}

\author{
https://doi.org/10.21272/sec.5(3).5-14.2021
}

Halil Dincer Kaya, ORCID: https://orcid.org/0000-0002-7535-9857

Professor of Finance, Department of Accounting and Finance, College of Business and Technology, Northeastern State University, Broken Arrow, OK, USA

\begin{abstract}
We examine the relationship between "primary employment" and "business friendliness" of U.S. states. Do states with a low score in "business friendliness" worry small business owners too much and hence force them to run their business as their primary job? We look at several main components of "business friendliness" including "Ease of start", "Ease of hire", "Overall regulations", and "Training and networking". We also look at subcomponents including the different types of regulations and technology use. How does each of these factors affect a business owner's decision to focus mainly on his/her business? We use the "United States Small Business Friendliness Survey" done by Kauffman Foundation and Thumptack.com in 2013 and converted the letter scores ranging from $\mathrm{A}+$ to $\mathrm{F}$ in the survey to numerical scores ranging from 12 to 1 (i.e. 1 being the lowest score which corresponds to F). Therefore, after the conversion, each state has a numerical score on each business-friendliness category. The survey also asks business owners if they use the internet when starting a business, when paying their taxes, or when licensing. For each state, we compute the percentage of owners in each state using the internet when starting a business, when paying their taxes, or when licensing. We call these three percentage numbers for each state their "Internetstart", "Internettax", and "Internetlicensing" scores. Then, using the mean score for all states for each type of regulation or internet score, we divide the states into two groups: the "high-score states" and the "low-score states". In our analysis, we use non-parametric tests to compare the "high-score states" to the "low-score states". Our non-parametric tests show that although none of the main components (i.e. "Ease of start", "Ease of hire", "Overall regulations", and "Training and networking") seem to affect "primary employment", the overall business friendliness score of a state significantly affects "primary employment". When we examine the different types of regulations, we find that "Health and safety regulations", "Licensing regulations", and "Zoning regulations" affect "primary employment". "Employment regulations", "Tax code", or "Environmental regulations" does not have a significant impact. These findings may indicate that business owners are more worried with regard to Health and safety regulations, Licensing regulations, and Zoning regulations, therefore more of them choose to take matters into their own hands. Another possible explanation may be the relative complexity of the tasks associated with these regulations. Finally, our results show that technology use in the entrepreneurial process does not affect "Primary employment".
\end{abstract}

Keywords: regulation, small firm, small business, entrepreneur, primary employment.

JEL Classification: G38, L22, L26.

Cite as: Kaya, H.D. (2021). The Determinants Of Primary Employment In U.S. States. SocioEconomic Challenges, 5(3), 5-14. https://doi.org/10.21272/sec.5(3).5-14.2021.

Received: 04.06.2021 Accepted: 19.08.2021 Published: 13.09.2021

Copyright: (C) 2021 by the author. Licensee Sumy State University, Ukraine. This article is an open access article distributed under the terms and conditions of the Creative Commons Attribution (CC BY) license (https://creativecommons.org/licenses/by/4.0/).

\section{Introduction}

In this study, we examine the relation between "primary employment" and "business friendliness" of U.S. states. A business owner having his/her business as "primary employment" is different from running the business as a 
side job or hobby. It is a stronger form of entrepreneurship than a business run as a side job/hobby because the entrepreneur generally uses more of his/her time, energy, and money in this form of entrepreneurship. Most of his/her livelihood depends on the business.

A business-friendly state supports entrepreneurs by making the process easier. For example, in these states, starting a business and hiring employees are easier compared to less business-friendly states. Also, these states have better training and networking programs to support entrepreneurs. The regulations in these states are also more supportive.

In this study, we differentiate between more business-friendly and less business-friendly states, and then compare the percentage of business owners who have their business as their primary job across these two groups of states. Do states with a low score in "business friendliness" worry business owners too much and therefore force them to run their business as their primary job? We look at several main components of "business friendliness" including "Ease of start", "Ease of hire", "Overall regulations", and "Training and networking". How do the states with a higher score in "Ease of start" differ from the states with a lower score in "Ease of start" in terms of primary employment? How do the states with a higher score in "Ease of hire" differ from the states with a lower score in "Ease of hire" in terms of primary employment? How do the states with a high score in "Overall regulations" or "Training and networking programs" differ from the states with a low score in these areas?

We also look at subcomponents including the different types of regulations and technology use. How does each type of regulation affect a business owner's decision to focus mainly on his/her business? How does the technology use during the entrepreneurial process affect a business owner's decision to focus mainly on his/her business?

The findings here will help policymakers substantially: In order to promote this stronger form of entrepreneurship (i.e. business as "primary employment"), what should policymakers focus their support on? Should they focus on improving "Ease of start", "Ease of hire", "Regulations", or "Training and networking programs"? Are certain types of regulations more important for the business owner's decision to focus solely on their business? How about technology use? If there is more and better technology involved in the entrepreneurial process (for example when starting a business or when paying taxes, etc.), do more or fewer owners choose to focus solely on their business?

In our analysis, we use the "United States Small Business Friendliness Survey" by Kauffman Foundation and Thumptack.com in 2013. This survey contains a question on whether the owners' business is their "primary employment". It also asks them questions about the components of business friendliness including "Ease of start", "Ease of hire", "Overall regulations", "Training and networking programs", and their subcomponents.

The paper proceeds as follows: The previous literature is summarized in Section 2. the data and the methodology are explained in Section 3. Section 4 shows our empirical results. Section 5 concludes.

\section{Literature Review}

In one of the earlier papers, Kourilsky and Walstad (2002) survey 1,001 owners/founders of high-technology businesses with under 200 employees and find that, for this group of entrepreneurs, the top six events associated with starting/owning a business are "Technology hobby" "Technology idea or opportunity/Inventing the system", "Past job or job experience", "Losing a job or becoming unemployed", "Need/Demand/Market at right time", and "Independence/Freedom/Be my own boss/Work at home".

Rantamaki-Lahtinen and Vihinen (2004) examine the transition of "hobby" entrepreneurs into regular business owners in the context of equine industries in Finland. The authors explain that entrepreneurs who move to the rural areas from elsewhere might see local business opportunities from a different angle. These people also have their own social networks that will get attached to local networks.

Cagetti and De Nardi (2006) look into the relationship between the type of entrepreneur and his/her wealth. They explain that the very rich entrepreneurs tend to be not active in the management of the firm. These entrepreneurs 
tend to see the business as an investment. On the other hand, the authors show that the poorest business owners tend to be the people who are doing this as a hobby or the low-wage workers who turn to self-employment for lack of better opportunities.

Okpara (2007) argues that creative entrepreneurs who have lots of energy and perseverance tend to transform a very simple idea or hobby into something more concrete. Shah and Tripsas (2007) examine "users" who later become "accidental" entrepreneurs when they come up with an idea through their own use and then share it with others.

Williams (2007) explains that informal business ventures may often arise from some hobby or interest. The author argues that "the systematic pursuit of an amateur, hobbyist or volunteer activity that participants find so substantial and interesting that they launch themselves on a career centered on acquiring and expressing its special skills".

Kerr and Nanda (2009) argue that most hobby entrepreneurs tend to avoid hiring someone else, remaining permanently in the lower bubble. Tambunan (2009) categorizes women entrepreneurs in Asian developing countries into three groups: forced entrepreneurs, chance entrepreneurs, and created or pulled entrepreneurs. The author explains that one of the motivations of chance entrepreneurs is their business being their hobby or special interest.

Folta et al. (2010) contend that some individuals may take on second jobs due to nonmonetary benefits which are not available in their primary jobs. Giacomin et al. (2011) examine the impact of the socio-economic characteristics of entrepreneurs on their opportunity-necessity positioning. They explain that some entrepreneurs are necessity driven while others that have a family influence are both necessity and opportunity driven. The authors describe "hobby entrepreneurship" as a new type of entrepreneurship.

Williams and Nadin (2012) explain that, in the informal economy, some of the new startup firms can derive from a hobby or interest. Williams and Round (2006) interviews a group of entrepreneurs in Ukraine and finds that one fifth of them use their hobby or interest as their starting point.

Heimonen (2013) explains that some entrepreneurs see their business as supplementary form of income where they seek both financial and personal success. The author explains that these entrepreneurs describe their motivations as having fun, doing what you want to do and at the same time earning some money, having a hobby and at the same time having an opportunity to earn money, having flexible working hours, and having an opportunity to maintain good health and functionality.

Rangarajan and Lakshmi (2013) argue that creativity and innovation are the keys to successful entrepreneurs. The authors survey entrepreneurs in India and show that these entrepreneurs production reflects a high level of creativity and innovation.

Block and Landgraf (2016) contend that part-time entrepreneurship is often a first step towards full-time entrepreneurship. They show that the motivation to achieve independence or self-realization is positively associated with transition behavior, whereas the motivation to supplement wage income or the motivation to achieve social recognition is negatively associated with transition behavior.

Warnick (2016) differentiates between entrepreneurial passion and domain passion. The author states that both are important startup investors. Anwar and Daniel (2016) examine home-based businesses and explain that unlike "hobby" businesses with little economic impact, home-based businesses make significant contribution to national economies in terms of both turnover and employment.

As summarized above, there are several previous papers on entrepreneurship as a hobby. These papers examine the motives of the entrepreneurs and also examine the process in which a hobby turns into a full-time job. The following section explains our data and methodology.

\section{Data and Methodology}

In this study, we use the "United States Small Business Friendliness Survey" done by Kauffman Foundation and Thumptack.com in 2013. This survey asks small business owners in the U.S. their opinions on the components of 
"business friendliness" which include "Ease of start", "Ease of hire", "Overall regulations", and "Training and networking". Then, the survey computes "Ease of start", "Ease of hire", "Overall regulations", and "Training and networking" scores for each U.S. state. Using these measures, the survey then computes a final overall score, which it calls "Overall score".

Each state's scores on "Ease of start", "Ease of hire", "Overall regulations", "Training and networking", and "Overall score" are available in the survey. However, the survey uses letter grades like A+, A, A-, B+, and so on. We convert these letter grades into numbers: A+ becomes 12; A becomes 11, and so on. The lowest letter grade is $\mathrm{F}$. After the conversion, $\mathrm{F}$ becomes 1 .

Besides these main factors that may affect startups, the survey goes deeper and asks more detailed questions about different types of regulations (i.e. "Health and safety regulations", "Employment regulations", "Tax code", "Licensing regulations", "Environmental regulations", and "Zoning regulations"). The survey computes each state's scores on these different types of regulations. However, again, the survey uses letter grades like A+, A, A, B+, and so on. I convert these letter grades into numbers: A+ becomes 12; A becomes 11, and so on. The lowest letter grade is $\mathrm{F}$. After the conversion, $\mathrm{F}$ becomes 1.

Besides the main factors and the different types of regulations, the survey also asks questions about the technology use by startups. From the individual responses, we compute the percentage of respondents in a state that have used the internet to form/start the business (we call this the "Internetstart" score for each state). Then, again from the individual responses, we compute the percentage of respondents in a state that have used the internet to pay the taxes on business earnings (we call this the "Internettax" score for each state). Finally, from the individual responses, we compute the percentage of respondents in a state that have used the internet to get a license or permit to do business (we call this the "Internetlicensing" score for each state).

Our objective is to examine whether the main factors, the different types of regulations, or the technology use in the process affects primary employment in a state. From the individual responses, we compute the percentage of small business owners that have their business as their primary job in each state, and we call this the "Primary employment" score for each state).

The variables are explained below:

Main variable:

Primary employment: the percentage of small business owners that have their business as their primary job.

Main factors:

Overall score: each state's overall business friendliness score as computed by the survey

Ease of start: each state's ease of start score as shown in the survey

Ease of hire: each state's ease of hire score as shown in the survey

Overall regulations: each state's overall regulations score as shown in the survey

Training and networking: each state's training \& networking score as shown in the survey

Different types of regulations:

Health and safety regulations: each state's score on health and safety regulations as computed by the survey

Employment regulations: each state's score on employment, labor and hiring regulations as computed by the survey

Tax code: each state's score on tax code and tax-related regulations as computed by the survey

Licensing regulations: each state's score on licensing forms, requirements and fees regulations as computed by the survey

Environmental regulations: each state's score on environmental regulations as computed by the survey 
Zoning regulations: each state's score on zoning regulations as computed by the survey

Technology use:

Internetstart: the percentage of respondents in a state that have used the internet to form/start the business (computed from the individual responses in each state)

Internettax: the percentage of respondents in a state that have used the internet to pay the taxes on business earnings (computed from the individual responses in each state)

Internetlicensing: the percentage of respondents in a state that have used the internet to get a license or permit to do business (computed from the individual responses in each state)

There are 41 states in our sample (we eliminated the states with insufficient data). These are Alabama, Arizona, Arkansas, California, Colorado, Connecticut, Florida, Georgia, Hawaii, Idaho, Illinois, Indiana, Iowa, Kansas, Kentucky, Louisiana, Maine, Maryland, Massachusetts, Michigan, Minnesota, Missouri, Nebraska, Nevada, New Hampshire, New Jersey, New Mexico, New York, North Carolina, Ohio, Oklahoma, Oregon, Pennsylvania, Rhode Island, South Carolina, Tennessee, Texas, Utah, Virginia, Washington, and Wisconsin.

First, we examine whether the states that have a high "Overall score" have a significantly different "Primary employment" score when compared to the states with a low "Overall score". For this purpose, we divide the U.S. states into two groups with regard to "Overall score". We classify the states with an "Overall score" that is higher than the average state's "Overall score" as "high score states" while we classify the other states as "low score states". Then, we examine whether the states that have a high "Ease of start" score have a significantly different "Primary employment" score when compared to the states with a low "Ease of start" score. We classify the states with an above-average "Ease of start" score as "high score states" while we classify the other states as "low score states". We follow the same process for each of the remaining variables. In the end, we have "high" and "low" score states with respect to "Overall score". We have "high" and "low" score states with respect to "Ease of start" score". We have "high" and "low" score states with respect to "Ease of hire" score, and so on. Of course, the states in the "high" score group with respect to "Overall score" are different from the states in the "high" score group with respect to "Ease of hire" score, and so on.

After creating our "high" and "low" score groups for each variable, we run nonparametric tests (i.e. MannWhitney-Wilcoxon tests) to compare the "Primary employment" scores in the "high" and "low" score groups.

Table 1 shows the summary statistics for each variable. The mean value of "Primary employment" is 71.96, meaning that in the average state, $71.96 \%$ of the respondents have their business as their primary job.

Table 1. Summary Statistics (All Variables in \%)

\begin{tabular}{|l|c|c|c|}
\hline \multicolumn{1}{|c|}{ Variable } & Mean & Median & Stdev \\
\hline Primary employment & 71.96 & 72.83 & 6.44 \\
\hline Overall score & 6.93 & 7.00 & 3.51 \\
\hline Ease of start & 6.93 & 7.00 & 3.51 \\
\hline Ease of hire & 7.02 & 7.00 & 3.54 \\
\hline Overall regulations & 6.98 & 7.00 & 3.47 \\
\hline Training and networking & 7.17 & 8.00 & 3.29 \\
\hline Health and safety regulations & 6.95 & 7.00 & 3.49 \\
\hline Employment regulations & 7.02 & 7.00 & 3.52 \\
\hline Tax code & 6.95 & 7.00 & 3.51 \\
\hline Licensing regulations & 7.02 & 7.00 & \\
\hline Environmental regulations & 6.93 & 3.55 \\
\hline Zoning regulations & 7.00 & 7.00 & 3.53 \\
\hline Internetstart & 58.21 & 58.62 & 3.46 \\
\hline Internettax & 34.54 & 34.78 & 6.39 \\
\hline Internetlicensing & 32.94 & 32.93 & 6.71 \\
\hline
\end{tabular}

Source: Author's own work 
As explained above, we converted the letter scores for the main factors and the regulations into numbers (i.e. A+ became 12, F became 1). We are seeing from the table that, among the main factors, the mean value of Training and networking is the highest (it is 7.17), meaning that the respondents, on average, gave the highest score to their state with respect to Training and networking (when compared to the other factors like Ease of start, Ease of hire, and Overall regulations). They were relatively happier with respect to training and networking opportunities. The lowest average score is for Ease of Start (6.93), meaning that the respondents were generally more pessimistic regarding the difficulty of starting a business in their state.

When we look at the different types of regulations, we are seeing that the respondents, on average, gave the highest score to their state with respect to Employment regulations and Licensing regulations (both are 7.02). The lowest score is for Environmental regulations (6.93). They were happier with employment and licensing regulations, but less happy with environmental regulations.

When we look at the technology use variables, we are seeing that more respondents (58.21\% in the average state) were using the internet to form/start a business, but fewer respondents were using the internet to pay the taxes (34.54\% in the average state) or to get a license/permit (32.94\% in the average state).

The next section shows the results of our empirical tests.

\section{Empirical Results}

Table 2 shows the relationship between "Primary employment" (i.e. the percentage of small business owners that have their business as their primary job) and "Overall score" on business friendliness. Table 2 also shows the relationship between "Primary employment" and each of the main components of "business friendliness" (i.e. Ease of start, Ease of hire, Overall regulations, and Training and networking").

Table 2. How Each Factor Affects Primary Employment

\begin{tabular}{|c|c|c|c|c|c|}
\hline & \multicolumn{2}{|c|}{ High-Score } & \multicolumn{2}{|c|}{ Low-Score } & \multirow{2}{*}{$\frac{\text { Mann-W. }}{\text { p-value }}$} \\
\hline Variable & Mean & Med. & Mean & Med. & \\
\hline \multicolumn{6}{|l|}{ Panel A. Overall Score } \\
\hline Primary employment & 70.52 & 72.59 & 73.81 & 74.11 & $* 0.0880$ \\
\hline \multicolumn{6}{|l|}{ Panel B. Ease of Start } \\
\hline Primary employment & 71.94 & 72.66 & 71.99 & 73.71 & 0.2270 \\
\hline \multicolumn{6}{|l|}{ Panel C. Ease of Hire } \\
\hline Primary employment & 73.03 & 73.03 & 70.94 & 72.59 & 0.1577 \\
\hline \multicolumn{6}{|l|}{ Panel D. Overall Regulations } \\
\hline Primary employment & 72.06 & 72.66 & 71.84 & 73.71 & 0.4843 \\
\hline \multicolumn{6}{|c|}{ Panel E. Training and Networking } \\
\hline Primary employment & 71.53 & 72.63 & 72.46 & 74.09 & 0.2960 \\
\hline
\end{tabular}

Source: Author's own work.

We are seeing that none of the main components of "business friendliness" (i.e. Ease of start, Ease of hire, Overall regulations, and Training and networking") have a significant impact on "Primary employment". There is no statistically significant difference between "High ease of start score" states and "Low ease of start score" states in terms of "Primary employment. While $71.94 \%$ of the respondents in the average state in the "high" group have their business as their primary job, the corresponding percentage is $71.99 \%$ in the "low" group ( $p=0.2270)$. Similarly, there is no statistically significant difference between "High ease of hire score" states and "Low ease of hire score" states in terms of "Primary employment. While $73.03 \%$ of the respondents in the average state in the "high" group have their business as their primary job, the corresponding percentage is $70.94 \%$ in the "low" group $(\mathrm{p}=0.1577)$. Similarly, there is no statistically significant difference between "High overall regulations score" states and "Low overall regulations score" states in terms of "Primary employment. While $72.06 \%$ of the respondents in the average state in the "high" group have their business as their primary job, the corresponding percentage is $71.84 \%$ in the "low" group $(p=0.4843)$. Finally, there is no statistically significant difference between "High training and networking score" states and "Low training and networking score" states in terms of 
"Primary employment. While $71.53 \%$ of the respondents in the average state in the "high" group have their business as their primary job, the corresponding percentage is $72.46 \%$ in the "low" group ( $\mathrm{p}=0.2960)$.

On the other hand, the table shows that "Overall score" on business friendliness has a significant impact on "Primary employment". The "Low overall score" group has significantly higher "Primary employment" when compared to the "High overall score" group. While only $70.52 \%$ of the respondents in the average state in the "high" group have their business as their primary job, the corresponding percentage is $73.81 \%$ in the "low" group $(\mathrm{p}=0.0880)$.

We conclude that although none of the main components has a significant impact on "Primary employment", the "Overall score" has a statistically significant impact on "Primary employment". We can argue that business owners are, on average, worried about their state's "business friendliness" (i.e. all of the hurdles in starting and running their business), therefore in the "low overall score states", we are seeing a larger proportion of owners focusing mainly on their business.

We can argue that, although business owners are not too worried about a particular hurdle in starting or running their business, still on average, they are worried in general about the overall picture (i.e. their state's overall "business friendliness"). As a result, in the "low overall score states", we are seeing a larger proportion of owners focusing mainly on their business.

Table 3 shows the relationship between "Primary employment" and the different types of regulations (i.e. "Health and safety regulations", "Employment regulations", "Tax code", "Licensing regulations", "Environmental regulations", and "Zoning regulations").

Table 3. The Impact of Regulations on Primary Employment

\begin{tabular}{|c|c|c|c|c|c|}
\hline & \multicolumn{2}{|c|}{ High-Score } & \multicolumn{2}{|c|}{ Low-Score } & \multirow{2}{*}{$\frac{\text { Mann-W. }}{\text { p-value }}$} \\
\hline Variable & Mean & Med. & Mean & Med. & \\
\hline \multicolumn{6}{|c|}{ Panel A. Health and Safety Regulations } \\
\hline Primary employment & 70.98 & 71.25 & 73.22 & 74.87 & $* * 0.0320$ \\
\hline \multicolumn{6}{|c|}{ Panel B. Employment Regulations } \\
\hline Primary employment & 70.89 & 72.57 & 72.99 & 74.13 & 0.1640 \\
\hline \multicolumn{6}{|l|}{ Panel C. Tax Code } \\
\hline Primary employment & 71.91 & 72.63 & 72.04 & 74.09 & 0.3605 \\
\hline \multicolumn{6}{|c|}{ Panel D. Licensing Regulations } \\
\hline Primary employment & 70.68 & 71.46 & 73.18 & 74.38 & $* * 0.0414$ \\
\hline \multicolumn{6}{|c|}{ Panel E. Environmental Regulations } \\
\hline Primary employment & 70.95 & 72.59 & 73.26 & 74.24 & 0.1623 \\
\hline \multicolumn{6}{|l|}{ Panel F. Zoning Regulations } \\
\hline Primary employment & 70.05 & 71.46 & 73.78 & 74.38 & $* * 0.0293$ \\
\hline
\end{tabular}

Source: Author's own work.

We are seeing that three types of regulations (i.e. Health and safety regulations, Licensing regulations, and Zoning regulations) have a significant impact on "Primary employment". In the states with below-average scores in Health and safety regulations, Licensing regulations, and Zoning regulations, we are seeing a larger proportion of owners focusing mainly on their business. With respect to Health and safety regulations, while $70.98 \%$ of the respondents in the average state in the "high" group have their business as their primary job, the corresponding percentage is $73.22 \%$ in the "low" group ( $\mathrm{p}=0.0320$ ). With respect to Licensing regulations, while $70.68 \%$ of the respondents in the average state in the "high" group have their business as their primary job, the corresponding percentage is $73.18 \%$ in the "low" group $(\mathrm{p}=0.0414)$. With respect to Zoning regulations, while $70.05 \%$ of the respondents in the average state in the "high" group have their business as their primary job, the corresponding percentage is $73.78 \%$ in the "low" group ( $\mathrm{p}=0.0293)$.

We do not see any significant difference in primary employment between "high" and "low" score states with respect to Employment regulations, Tax code, and Environmental regulations. 
These findings may indicate that business owners are more worried with regard to Health and safety regulations, Licensing regulations, and Zoning regulations, therefore more of them choose to take matters into their own hands. Another possible explanation may be the relative complexity of the tasks associated with these regulations when compared to the tasks associated with the other regulations. For example, with Health and safety regulations, a more detailed attention to may be needed. For Licensing and Zoning regulations, the owner may need to establish more close connections/relationships with the officials and this would require more time by the owner. On the other hand, Employment regulations, Tax code, and Environmental regulations are more straightforward. The rules are clear and well-known for Employment regulations. The tax issues are handled by an accountant. Environmental regulations rarely create an issue for a small business owner.

Table 4 shows the relationship between "Primary employment" and technology use in entrepreneurial process (i.e. "Internetstart", "Internettax", and "Internetlicensing"). The results are insignificant. The states that have high scores in technology use (or more specifically internet use) do not differ from the other states with respect to primary employment. With respect to "Internetstart", while $71.02 \%$ of the respondents in the average state in the "high" group have their business as their primary job, the corresponding percentage is $73.44 \%$ in the "low" group $(\mathrm{p}=0.2075)$. With respect to "Internettax", while $72.35 \%$ of the respondents in the average state in the "high" group have their business as their primary job, the corresponding percentage is $71.47 \%$ in the "low" group $(\mathrm{p}=0.3419)$. With respect to "Internetlicensing", while $71.51 \%$ of the respondents in the average state in the "high" group have their business as their primary job, the corresponding percentage is $72.40 \%$ in the "low" group $(\mathrm{p}=0.3335)$.

Table 4. How Technology Use Affects Primary Employment

\begin{tabular}{|c|c|c|c|c|c|}
\hline & \multicolumn{2}{|c|}{ High-Score } & \multicolumn{2}{|c|}{ Low-Score } & \multirow{2}{*}{$\begin{array}{c}\text { Mann-W } \\
\text { p-value }\end{array}$} \\
\hline Variable & Mean & Med. & Mean & Med. & \\
\hline \multicolumn{6}{|l|}{ Panel A. Internetstart } \\
\hline Primary employment & 71.02 & 72.54 & 73.44 & 74.26 & 0.2075 \\
\hline \multicolumn{6}{|l|}{ Panel B. Internettax } \\
\hline Primary employment & 72.35 & 72.54 & 71.47 & 74.26 & 0.3419 \\
\hline \multicolumn{6}{|l|}{ Panel C. Internetlicensing } \\
\hline Primary employment & 71.51 & 73.08 & 72.40 & 72.66 & 0.3335 \\
\hline
\end{tabular}

Source: Author's own work.

There is no statistically significant difference in terms of primary employment between the states with high scores in internet use and the states with low scores in internet use. The decision to focus mainly on the business versus doing it as a secondary job does not seem to be affected by a state's offering of technology in order to ease the entrepreneurial process.

\section{Conclusion}

In this study, we examine the relationship between "primary employment" and "business friendliness" of U.S. states. Do small business owners in "less business-friendly states" worry so much that they take matters into their own hands?

To achieve our objective, we use the "United States Small Business Friendliness Survey" done by Kauffman Foundation and Thumptack.com in 2013. This survey asks small business owners their opinions on the main components of "business friendliness" which include "Ease of start", "Ease of hire", "Overall regulations", and "Training and networking". Then, the survey computes letter scores for each of these main components for each U.S. state. The highest score given is A+ and the lowest score given is F. Using these measures, the survey then computes a final overall score, which it calls "Overall score". We convert each state's letter scores to numerical scores (the highest score $\mathrm{A}+$ is now 12 and the lowest score $\mathrm{F}$ is now 1).

The survey also asks business owners their opinions on their state's different types of regulations (i.e. "Health and safety regulations", "Employment regulations", "Tax code", "Licensing regulations", "Environmental regulations", and "Zoning regulations") which are actually subcomponents of "business friendliness". Again, the survey computes letter scores for each of these regulations for each U.S. state. The highest score given is A+ and 
the lowest score given is F. Again, we convert each state's letter scores to numerical scores (the highest score A+ is now 12 and the lowest score $\mathrm{F}$ is now 1 ).

The survey also asks business owners if they use the internet when starting a business, when paying their taxes, or when licensing. For each state, we compute the percentage of owners in each state using the internet when starting a business, when paying their taxes, or when licensing. We call these three percentage numbers for each state their "Internetstart", "Internettax", and "Internetlicensing" scores.

Our objective is to see how each of these components and subcomponents affect a business owner's decision to focus mainly on his/her business. Our non-parametric tests show that although none of the main components (i.e. "Ease of start", "Ease of hire", "Overall regulations", and "Training and networking") seem to affect "primary employment", the overall business friendliness score of a state significantly affects "primary employment". We argue that, although business owners are not too worried about a particular main component in starting or running their business, still on average, they are worried in general about the overall picture (i.e. their state's overall "business friendliness"). As a result, in the "low overall score states", we are seeing a larger proportion of owners focusing mainly on their business.

When we examine the different types of regulations, we find that three types of regulations were important for "primary employment". These are "Health and safety regulations", "Licensing regulations", and "Zoning regulations". These regulations affect "primary employment". On the other hand, our results show that "Employment regulations", "Tax code", or "Environmental regulations" does not have a significant impact on "primary employment". These results may indicate that business owners are more worried with regard to Health and safety regulations, Licensing regulations, and Zoning regulations, therefore more of them choose to take matters into their own hands. Another possible explanation may be the relative complexity of the tasks associated with these regulations (i.e. more time and more close attention is needed by the owners).

When we examine how technology use in the entrepreneurial process (i.e. "Internetstart", "Internettax", and "Internetlicensing") affects "primary employment". Our results show that technology use in the entrepreneurial process does not affect "Primary employment" significantly.

We conclude that "business friendliness" and certain types of regulations are seen as serious hurdles by the business owners. Therefore, in the states with low scores in these areas, we are seeing more owners taking matters into their own hands. These findings imply that policymakers should focus more on improving these areas (i.e. Health and safety regulations, Licensing regulations, and Zoning regulations). They also need to improve the overall picture because the overall business friendliness score seems to matter.

We argue that business owners feel too much pressure in these areas, therefore they try to allocate more of their time, energy and resources into their business. In other words, we see a high percentage of "primary employment" in a state as a sign of "distress" for small business owners in that state. Future research may focus on other personal characteristics of small business owners which may impact their decision to take matters into their own hands. For example, does age or experience matter? Does education level of the entrepreneur matter? These and other personal factors may influence the decision.

Funding: self-funded.

Author contribution: conceptualization, Halil Dincer Kaya; data curation, Halil Dincer Kaya; formal analysis, Halil Dincer Kaya; funding acquisition, Halil Dincer Kaya; investigation, Halil Dincer Kaya; methodology, Halil Dincer Kaya; project administration, Halil Dincer Kaya; resources, Halil Dincer Kaya; software, Halil Dincer Kaya; supervision, Halil Dincer Kaya; validation, Halil Dincer Kaya; visualization, Halil Dincer Kaya; writing original draft, Halil Dincer Kaya; writing - review \& editing, Halil Dincer Kaya. 


\section{References}

1. Anwar, Naveed, and Elizabeth Daniel (2016). The Role of Entrepreneur-Venture Fit in Online Home-based Entrepreneurship: A Systematic Literature Review. Journal of Enterprising Culture, 24(4), p. 419. [Google Scholar], [CrossRef], [Link].

2. Block, Jörn H., and Andreas Landgraf (2016). Transition from part-time entrepreneurship to full-time entrepreneurship: the role of financial and non-financial motives. International Entrepreneurship and Management Journal, 12(1), 259-282. [CrossRef], [Link].

3. Cagetti, Marco, and Mariacristina De Nardi (2006). Entrepreneurship, frictions, and wealth. Journal of political Economy, 114(5), 835-870. [CrossRef], [Link].

4. Folta, Timothy B., Frédéric Delmar, and Karl Wennberg (2010). Hybrid entrepreneurship. Management Science, 56(2), 253-269. Available at: [Link].

5. Giacomin, Olivier, Frank Janssen, Jean-luc Guyot, and Olivier Lohest (2011). Opportunity and/or necessity entrepreneurship? The impact of the socio-economic characteristics of entrepreneurs. [Google Scholar].

6. Heimonen, Tomi (2013). Entrepreneurship in Golden Years-Creative Opportunity or Not? China-USA Business Review, 12(1). [Google Scholar].

7. Kerr, William, and Ramana Nanda (2009). Financing constraints and entrepreneurship. No. w15498. National Bureau of Economic Research. [CrossRef].

8. Kourilsky, Marilyn L., and William B. Walstad (2002). The early environment and schooling experiences of high-technology entrepreneurs: Insights for entrepreneurship education. International Journal of Entrepreneurship Education, 1(1), 1-20. [Google Scholar].

9. Okpara, Friday O. (2007). The value of creativity and innovation in entrepreneurship. Journal of Asia Entrepreneurship and Sustainability, 3(2), 1. Available at: [Link].

10. Rangarajan, R., and R. Lakshmi (2013). Creativity and Innovation in Entrepreneurship-A Brief Assessment. Sumedha Journal of Management, 2(4), 55. [CrossRef].

11. Rantamaki-Lahtinen, L., and Hilkka Vihinen (2004). The role of equine industries in Finnish rural development - rural entrepreneurship and policy perspectives. Nordic Association of Agricultural Scientists: Horse Management - Premises and Landscape (Seminar 367). [CrossRef].

12. Shah, Sonali K., and Mary Tripsas (2007). The accidental entrepreneur: The emergent and collective process of user entrepreneurship. Strategic Entrepreneurship Journal, 1(1-2), 123-140. Available at: [Link].

13. Tambunan, Tulus (2009). Women entrepreneurship in Asian developing countries: Their development and main constraints. Journal of Development and Agricultural Economics, 1(2), 027-040. Available at: [Link].

14. Warnick, Benjamin J. (2016). Passion for product, process, or both? Expanding our conception of passion in entrepreneurship. Diss. Indiana University. Avaailable at: [Link].

15. Williams, Colin C. (2007). The nature of entrepreneurship in the informal sector: evidence from England. Journal of Developmental Entrepreneurship, 12(02), 239-254[Google Scholar], [Crossref].

16. Williams, Colin C., and Sara J. Nadin (2012). Tackling entrepreneurship in the informal economy: evaluating the policy options. Journal of Entrepreneurship and Public Policy, 1(2), 111-124. [Google Scholar], [CrossRef].

17. Williams, Colin C., and John Round (2007). Entrepreneurship and the informal economy: a study of Ukraine's hidden enterprise culture. Journal of Developmental Entrepreneurship, 12(01), 119-136. [Google Scholar], [CrossRef], [Link]. 